Article

\title{
Identification and Expression Analysis of Polygalacturonase Family Members during Peach Fruit Softening
}

\author{
Ming Qian, Yike Zhang, Xiangyan Yan, Mingyu Han, Jinjin Li, Fang Li, Furui Li, Dong Zhang \\ and Caiping Zhao*
}

College of Horticulture, Northwest A\&F University, Yangling 712100, China; m13637099856@163.com (M.Q.); 18821635518@163.com (Y.Z.); xiangyan0209@163.com (X.Y.); hanmy@nwsuaf.edu.cn (M.H.); lijinjin@bigizy.cn (J.L.); fangfang0918@126.com (Fa.L.); 18821635911@163.com (Fu.L.); afant@nwsuaf.edu.cn (D.Z.)

* Correspondence: zhcc@nwsuaf.edu.cn; Tel.: +86-582-969-2182

Academic Editor: María Serrano

Received: 12 September 2016; Accepted: 7 November 2016; Published: 18 November 2016

\begin{abstract}
Polygalacturonase (PG) is an important hydrolytic enzyme involved in pectin degradation during fruit softening. However, the roles of $P G$ family members in fruit softening remain unclear. We identified 45 PpPG genes in the peach genome which are clustered into six subclasses. PpPGs consist of four to nine exons and three to eight introns, and the exon/intron structure is basically conserved in all but subclass E. Only 16 PpPG genes were expressed in ripening fruit, and their expression profiles were analyzed during storage in two peach cultivars with different softening characteristics. Eight PGs (PpPG1, -10, -12,-13, -15, -23, -21, and -22) in fast-softening "Qian Jian Bai" (QJB) fruit and three PGs (PpPG15, -21, and -22) in slow-softening "Qin Wang" (QW) fruit exhibited softening-associated patterns; which also were affected by ethylene treatment. Our results suggest that the different softening characters in QW and QJB fruit is related to the amount of PG members. While keeping relatively lower levels during QW fruit softening, the expression of six PGs (PpPG1, $-10,-12,-11,-14$, and -35) rapidly induced by ethylene. PpPG24, -25 and -38 may not be involved in softening of peach fruit.
\end{abstract}

Keywords: peach; PG family; fruit; softening; ripening

\section{Introduction}

Fruit maturation is a complex and highly coordinated developmental process. In fleshy fruits, the main changes associated with ripening affect color, firmness, taste and flavor, and increase not only palatability, but also susceptibility to physical damage and shortening of storage life [1,2]. Peach is a typical climacteric fruit, and rapid softening and short shelf life after harvest adversely affect its market value [3]. Therefore, studying the physiological and molecular processes governing the softening of peach would be greatly beneficial in extending its shelf life.

Modification of the cell wall is thought to underlie the changes in fruit firmness and texture [4]. Plant cell wall is a complex reticulate structure, being composed of cellulose, hemicellulose, pectin and structural proteins [5,6]. Among these four macromolecular substances, pectin is the major component in the middle lamella and cell primary wall and can link cells together like "glue" [7-10]. Thus, systematic disassembly of pectin is critical to some developmental processes in plants, such as organ abscission, fruit ripening, and pod and anther dehiscence [11,12]. The degradation of pectin is catalyzed by hydrolytic enzymes, mainly including polygalacturonase (PG), pectate lyase, pectin methylesterases and $\beta$-galactosidase, of which PG has been suggested to play a central role $[11,13]$. 
Involvement of PG in fruit softening has been widely reported. In strawberry, silencing of FaPG1 gene decreases the breakdown of the middle lamella and slows the fruit softening [14]. In pear and banana, fruits softening are positively regulated by Pc-PG1 and Pc-PG2, and MaPG3 and MaPG4, respectively, with a pattern of ethylene-dependent $[15,16]$. The similar results have also been observed in papaya, guava, capsicum and apple [17-20]. However, Smith et al. thought $P G$ was not essential for tomato fruit softening [21]. Interestingly, peach fruit melting and freestone are also controlled by Endo-PGs [22-25]. In addition, $P G$ genes also participate in the organ abscission of lychee, oilseed rape, Arabidopsis and tomato [26-28]. In Arabidopsis, QUARTET2 (QRT2) is involved in pollen grain separation [29], and ADPG1 and ADPG2 are related to silique dehiscence and floral organ abscission [30].

PGs belong to one of the largest hydrolase families in plants [31], and the $P G$ gene family has been identified in various plant species, including Arabidopsis [29], Oryza sativa [31], Populus [32], Cucumis sativus and Citrullus lanatus [33]. The expression of 66 PG genes of Arabidopsis has been tested by RT-PCR in five tissues, flowers, siliques, stems, leaves and roots, but only 43 had PCR products, 40 in flower, 34 in silique and root, 30 in leaf and 31 in stem [31]. In Populus, 11 PG members are related to flower development and two are related to leaf abscission under salt stress [32]. In Cucumis sativus, most CsPGs exhibit specific or high expression levels in a particular organ or tissue [33]. These studies have demonstrated that $P G$ members are differentially expressed in specific tissues and in response to specific treatments, indicating extensive functional divergence among plant $P G$ genes. Although the important roles of PG hydrolase in peach softening were confirmed by many researches $[3,4,34]$, only a small number of $P G$ family members have been reported $[25,34-36]$. To clarify which $P G$ members are involved in softening of peach fruit, in this study, we identify 45 members of the $P G$ family from the whole genomic sequence of peach and analyze the expression profiles of $P p P G$ genes during fruit softening in two peach cultivars that have different softening characteristics. We identify a small subset of $P G$ genes that display consistent softening-associated expression patterns. We investigate the connection between selected ripening- and softening-related $P G$ genes and the mechanism underlying ethylene-dependent ripening.

\section{Results}

\subsection{Identification of Polygalacturonase (PG) Family Members in Peach}

The Hidden Markov Model (HMM) profile of the glycosyl hydrolase family 28 (GH28) domain was used as a query to blast against the NCBI non-redundant protein database and the Peach Genome Database. All reported Arabidopsis PG proteins were also used to search against the peach genome database using NCBI tblastn. Then, all candidate $P G$ family members in the peach genome database were identified using four highly conserved $P G$ domains. Forty-five $P G$ genes were identified in peach and named PpPG1-45 according to their chromosomal location (Table 1). Most $P G$ family members (32 members) contained the conserved domains I, II, III and IV. PpPG11, -12, -13, -15, -16, -23, -24, -25 and -38 lacked domain III. PpPG9 and -32 did not contain domain IV. PpPG37 and -44 lacked domains III and IV, and II and III, respectively (Figure 1).

The open reading frame (ORF) lengths of the 45 PpPG family members ranged from 879 to $1866 \mathrm{bp}$, and the deduced polypeptide sequences ranged in length from 292 to 621 amino acids, with predicted molecular weights $\left(M_{\mathrm{W}}\right)$ between 30.66 and $65.91 \mathrm{kDa}$. The predicted isoelectric points (pIs) of PpPGs ranged from 4.88 to 9.53. SignalP 3.0 analysis revealed that PpPG1, $-5,-6,-8,-11,-12,-13,-14,-16,-18$, $-20,-21,-22,-23,-24,-25,-34,-36,-37,-41,-42,-44$ and -45 contained a signal peptide (Table 1 ). 
Table 1. Peach PG genes identified in this study.

\begin{tabular}{|c|c|c|c|c|c|c|c|}
\hline \multirow[b]{2}{*}{$\begin{array}{l}\text { Gene } \\
\text { Name }\end{array}$} & \multirow[b]{2}{*}{ Gene ID } & \multirow[b]{2}{*}{ Description } & \multicolumn{3}{|c|}{ Deduced Polypeptide } & \multirow{2}{*}{$\begin{array}{l}\text { Signal } \\
\text { Peptide }\end{array}$} & \multirow[b]{2}{*}{ Domains } \\
\hline & & & $\begin{array}{l}\text { Length } \\
\text { (aa) }\end{array}$ & $\begin{array}{l}M_{\mathrm{W}} \\
(\mathrm{kDa})\end{array}$ & PI & & \\
\hline PpPG1 & ppa018113m & Polygalacturonase At1g48100 & 510 & 54.48 & 6.7 & + & I, II, III, IV \\
\hline PpPG2 & ppa005391m & Polygalacturonase At1g48100 & 463 & 50.16 & 4.88 & - & I, II, III, IV \\
\hline PpPG3 & ppa026115m & Exopolygalacturonase clone GBGE184 & 376 & 40.07 & 8.84 & - & I, II, III, IV \\
\hline PpPG4 & ppa015208m & Exopolygalacturonase clone GBGE184 & 376 & 40.06 & 8.74 & - & I, II, III, IV \\
\hline PpPG5 & ppa1027214m & - & 470 & 51.15 & 9.53 & + & I, II, III, IV \\
\hline PpPG6 & ppa004002m & Polygalacturonase At1g48100 & 536 & 57.83 & 8.8 & + & I, II, III, IV \\
\hline PpPG7 & ppa015822m & Probable polygalacturonase At3g15720 & 379 & 40.23 & 7.23 & - & I, II, III, IV \\
\hline PpPG8 & ppa015678m & Probable polygalacturonase At3g15720 & 390 & 41.35 & 6.35 & + & I, II, III, IV \\
\hline PpPG9 & ppa017135m & Polygalacturonase & 292 & 30.67 & 6.28 & - & I, II, III \\
\hline PpPG10 & ppa026655m & Polygalacturonase & 375 & 40.83 & 9.09 & - & I, II, III, IV \\
\hline PpPG11 & ppa018224m & Probable polygalacturonase & 463 & 50.68 & 6.56 & + & I, II, IV \\
\hline PpPG12 & ppa020086m & Probable polygalacturonase & 517 & 55.99 & 8.91 & + & I, II, IV \\
\hline PpPG13 & ppa005310m & Probable polygalacturonase & 467 & 51.58 & 5.74 & + & I, II, IV \\
\hline PpPG14 & ppa014982m & Probable polygalacturonase At1g80170 & 449 & 48.85 & 8.74 & + & I, II, III, IV \\
\hline PpPG15 & ppa018901m & Probable polygalacturonase & 391 & 42.72 & 6.66 & - & I, II, IV \\
\hline PpPG16 & ppa005185m & Probable polygalacturonase & 473 & 52.28 & 8.73 & + & I, II, IV \\
\hline PpPG17 & ppa024649m & Polygalacturonase At1g48100 & 437 & 47.60 & 5.95 & - & I, II, III, IV \\
\hline PpPG18 & ppa021095m & Probable polygalacturonase At3g15720 & 621 & 65.91 & 6 & + & I, II, III, IV \\
\hline PpPG19 & ppa021953m & Polygalacturonase & 376 & 39.46 & 8.35 & - & I, II, III, IV \\
\hline PpPG20 & ppa025787m & Polygalacturonase & 392 & 40.98 & 9.28 & + & I, II, III, IV \\
\hline PpPG21 & ppa006839m & Polygalacturonase & 393 & 41.33 & 6.24 & + & I, II, III, IV \\
\hline PpPG22 & ppa006857m & Polygalacturonase & 393 & 41.26 & 6.24 & + & I, II, III, IV \\
\hline PpPG23 & ppa005015m & Probable polygalacturonase & 481 & 52.39 & 6.36 & + & I, II, IV \\
\hline PpPG24 & ppa004996m & Probable polygalacturonase & 482 & 52.45 & 5.81 & + & I, II, IV \\
\hline PpPG25 & ppa005818m & Probable polygalacturonase & 442 & 48.32 & 7.12 & + & I, II, IV \\
\hline PpPG26 & ppa019727m & Probable polygalacturonase At3g15720 & 382 & 41.13 & 8.66 & - & I, II, III, IV \\
\hline PpPG27 & ppa025098m & Polygalacturonase & 384 & 40.72 & 7.54 & - & I, II, III, IV \\
\hline PpPG28 & ppa014719m & Polygalacturonase At1g48100 & 419 & 45.94 & 8.27 & - & I, II, III, IV \\
\hline PpPG29 & ppa025464m & Polygalacturonase & 381 & 40.56 & 8.76 & - & I, II, III, IV \\
\hline PpPG30 & ppa016722m & Polygalacturonase & 432 & 46.30 & 8.72 & - & I, II, III, IV \\
\hline PpPG31 & ppa018682m & Polygalacturonase & 371 & 39.42 & 8.17 & - & I, II, III, IV \\
\hline PpPG32 & ppa018149m & Polygalacturonase & 307 & 33.04 & 8.18 & - & I, II, III \\
\hline PpPG33 & ppa018308m & Polygalacturonase & 376 & 39.92 & 7.89 & - & I, II, III, IV \\
\hline PpPG34 & ppa023489m & Probable polygalacturonase At3g15720 & 436 & 46.94 & 7.84 & + & I, II, III, IV \\
\hline PpPG35 & ppa022427m & Polygalacturonase & 431 & 46.44 & 5.81 & - & I, II, III, IV \\
\hline PpPG36 & ppa018519m & Probable polygalacturonase At3g15720 & 405 & 43.79 & 5.82 & + & I, II, III, IV \\
\hline PpPG37 & ppa005960m & Probable polygalacturonase & 435 & 47.64 & 5.75 & + & I, II \\
\hline PpPG38 & ppa004793m & Probable polygalacturonase & 491 & 55.03 & 9.15 & - & I, II, IV \\
\hline PpPG39 & ppa021427m & Probable polygalacturonase At3g15720 & 383 & 41.32 & 7.92 & - & I, II, III, IV \\
\hline PpPG40 & ppa007271m & Polygalacturonase & 375 & 38.92 & 8.51 & - & I, II, III, IV \\
\hline PpPG41 & ppa020072m & Polygalacturonase & 395 & 42.03 & 9.52 & + & I, II, III, IV \\
\hline PpPG42 & ppa016502m & Polygalacturonase & 403 & 42.82 & 9.24 & + & I, II, III, IV \\
\hline PpPG43 & ppa019563m & Exopolygalacturonase & 387 & 41.55 & 8.93 & - & I, II, III, IV \\
\hline PpPG44 & ppb019654m & Polygalacturonase & 382 & 30.80 & 8.81 & + & I, IV \\
\hline PpPG45 & ppa015568m & Exopolygalacturonase clone GBGE184 & 482 & 50.57 & 6.32 & + & I, II, III, IV \\
\hline
\end{tabular}

\subsection{Phylogenetic Analysis of PG Family Members in Peach}

The phylogenetic tree was created using MEGA 6.0 with full-length PG protein sequences from peach, Arabidopsis thaliana and some selected fruit species. The 45 peach PG proteins were clustered into six subclasses (subclasses A to F). Subclass G was Arabidopsis QRT3PG, which is involved in degradation of the pollen mother cell wall [37], and did not include any peach $P G$ members. Most peach $P G$ members were included in subclasses $C$ and $E$, while fewer members were included in subclasses B and D. PpPG21 and -22 were similar to PdPG; PpPG12 and -15 were similar to LcPG; and PpPG1 and -10 were similar to VvPG1 and CmPG1, respectively (Figure 2). We defined the most likely orthologs between peach and Arabidopsis. This suggested that there were at least 25 ancestral PGs before the divergence of other species and peach (Figure 2, red circles). Three of these nodes in subclasses of B, E and F, respectively (Figure 2, black circles), however, had relatively low bootstrap support $(<50 \%)$. 
$P p P G 9,-29,-30,-31,-32$, and -33 in subclass $\mathrm{C}$, and $P p P G 7,-8,-18,-26,-34$, and -36 in subclass $\mathrm{F}$, formed two special sub-clades without other species members (Figure 2).



Figure 1. Multiple sequence alignment of peptides of peach PGs. Blue shading and underlining indicates four typical conserved domains of PGs, referred to as domains I, II, III and IV. The consensus sequence is shown by letter logos. Different colors indicate different similarities (black: 100\%, Magenta: $\geq 75 \%$, cyan: $\geq 50 \%$ ).

\subsection{Genome Distribution and Gene Structures of PG Family Members in Peach}

$P G$ gene family members are distributed on all peach chromosomes. Chr 7 contains 14 PpPG genes; chr 1 and chr 4, and chr 6 and chr 8 contain seven PpPG genes and three PpPG genes, respectively; chr 2 contains four; chr 3 contains five; and chr 5 contains two. We can also observe tandem duplication sites such as PpPG8 and -7 on chr 1, and PpPG19, -20,-21 and -22 on chr 4 (Figure 3).

All peach PG protein sequences were used to construct an unrooted phylogenetic tree with MEGA 6.0, and it was consistent with the rooted tree described above (Figure 4). The exon/intron structures and intron phase of peach $P G$ genes were analyzed using the online tool GSDS, using their full-length CDS sequences and corresponding genomic DNA sequences. The results showed that $P p P G s$ consisted of four to nine exons and three to eight introns, and the members of subclasses A, B and F generally had more exons and introns. In addition, the exon/intron structure is basically conserved in each subclass except for subclass E (Figure 4).

To further investigate conserved motifs in the amino acid sequences of peach $P G$ genes, 45 peach PG proteins were aligned using the online tool MEME set to output eight motifs. Motif 1 was found in all 45 peach $P G$ members, while motif 4 was absent in PpPG32, motif 3 was absent in PpPG9 and -37, and motif 7 was absent in PpPG32 and -45. Some motifs only existed in certain members, such as motif 2 , which existed in most $P p P G$ members, but not in subclass E. Moreover, most members of subclass $\mathrm{E}$ were also missing motif 5 and motif 8 . Furthermore, $P p P G 44$ in subclass $B$ did not have motifs 2,5 or 8 ; $P p P G 9$ in subclass $C$ did not have motifs 3 or 6 , and $P p P G 32$ had only four motifs (Figure 4). 


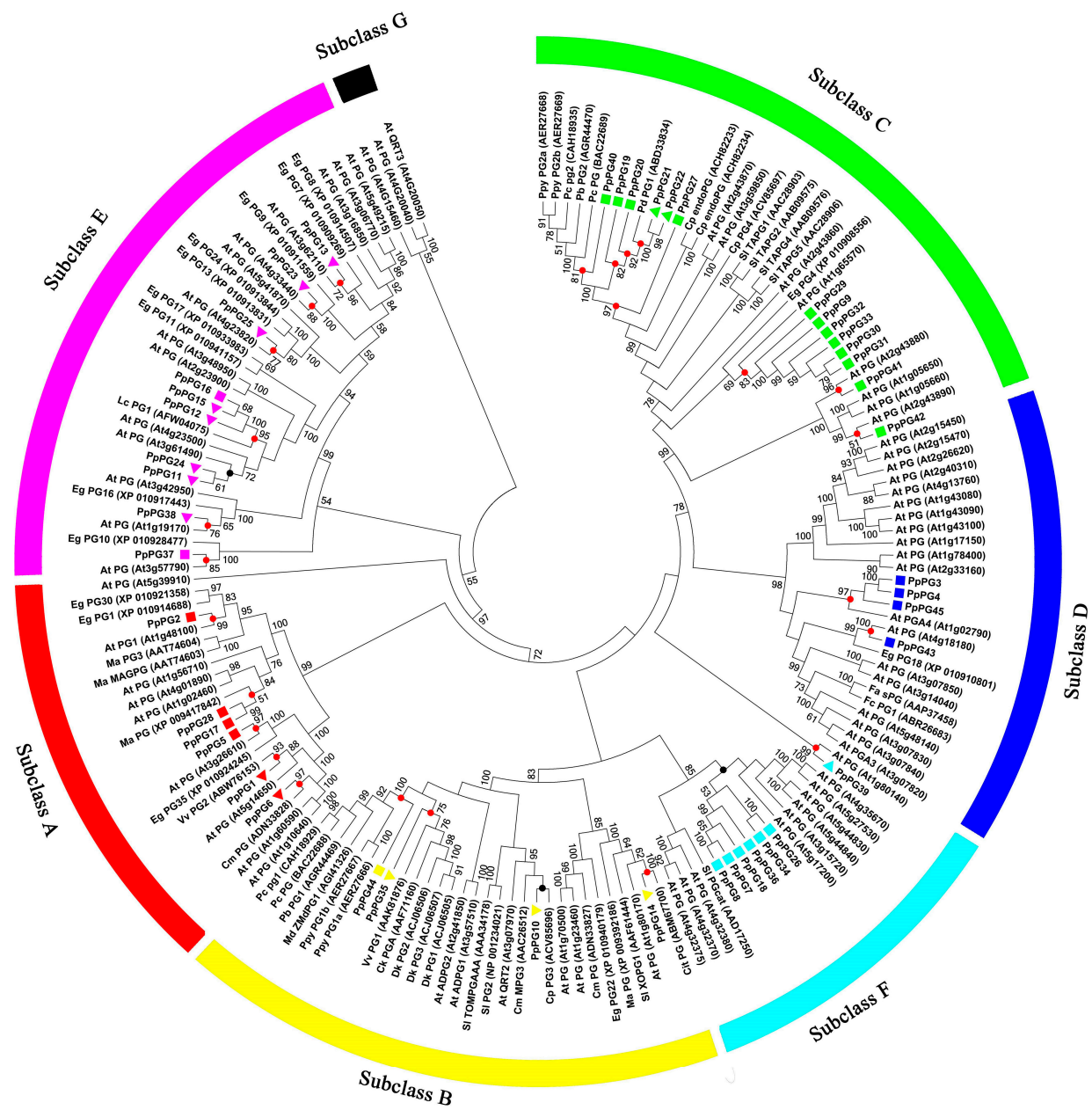

Figure 2. Phylogenetic tree of PGs from Prunus persica and other species. Species shown are Carica papaya (CpPG), Citrus sinensis (CitPG), Cucumis melo (CmPG), Diospyros kaki (DkPG), Fragaria chiloensis (FcPG), Arabidopsis thaliana (AtPG), Fragaria $\times$ ananassa (FaPG), Actinidia chinensis (CkPGA), Litchi chinensis (LcPG), Malus domestica (MdPG), Musa acuminate (MaPG), Prunus domestica subsp. insititia (PdPG), Pyrus communis (PcPG), Pyrus bretschneideri (PbPG), Pyrus pyrifolia (PpyPG), Solanum lycopersicum (SIPG), Elaeis guineensis (EgPG) and Vitis vinifera (VvPG). Colored triangles and squares represent $P p P G s$ and each color indicates a subclass; triangles indicate $P p P G$ genes that are expressed in peach fruit and squares represent $P p P G$ s that are not expressed in peach fruit according to results of RNA-seq. Red and black nodes indicate that the bootstrap support for the branches defining the common ancestral PGs is more than $50 \%$ and less than $50 \%$, respectively. Bootstrap values lower than 50 are hidden in the unrooted phylogenetic tree.
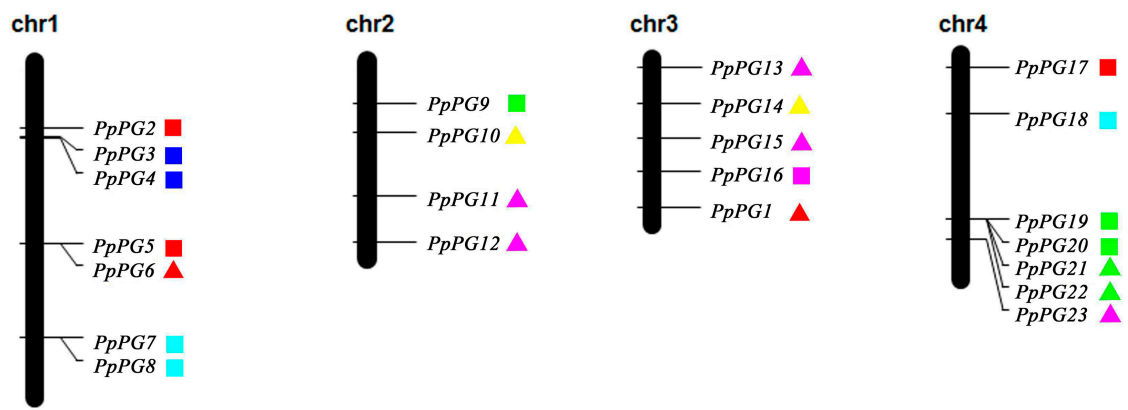

Figure 3. Cont. 

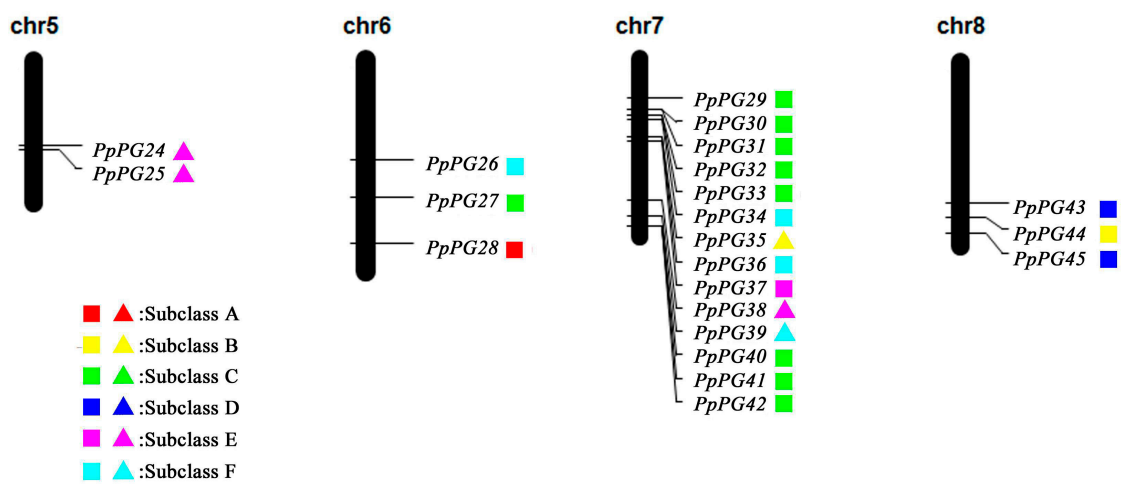

Figure 3. Chromosomal mapping of peach $P G$ genes. Each subclass is shown by different color. Triangles, $P p P G$ genes expressed in peach fruit; squares, $P p P G$ s not expressed in peach fruit, according to results of RNA-seq.

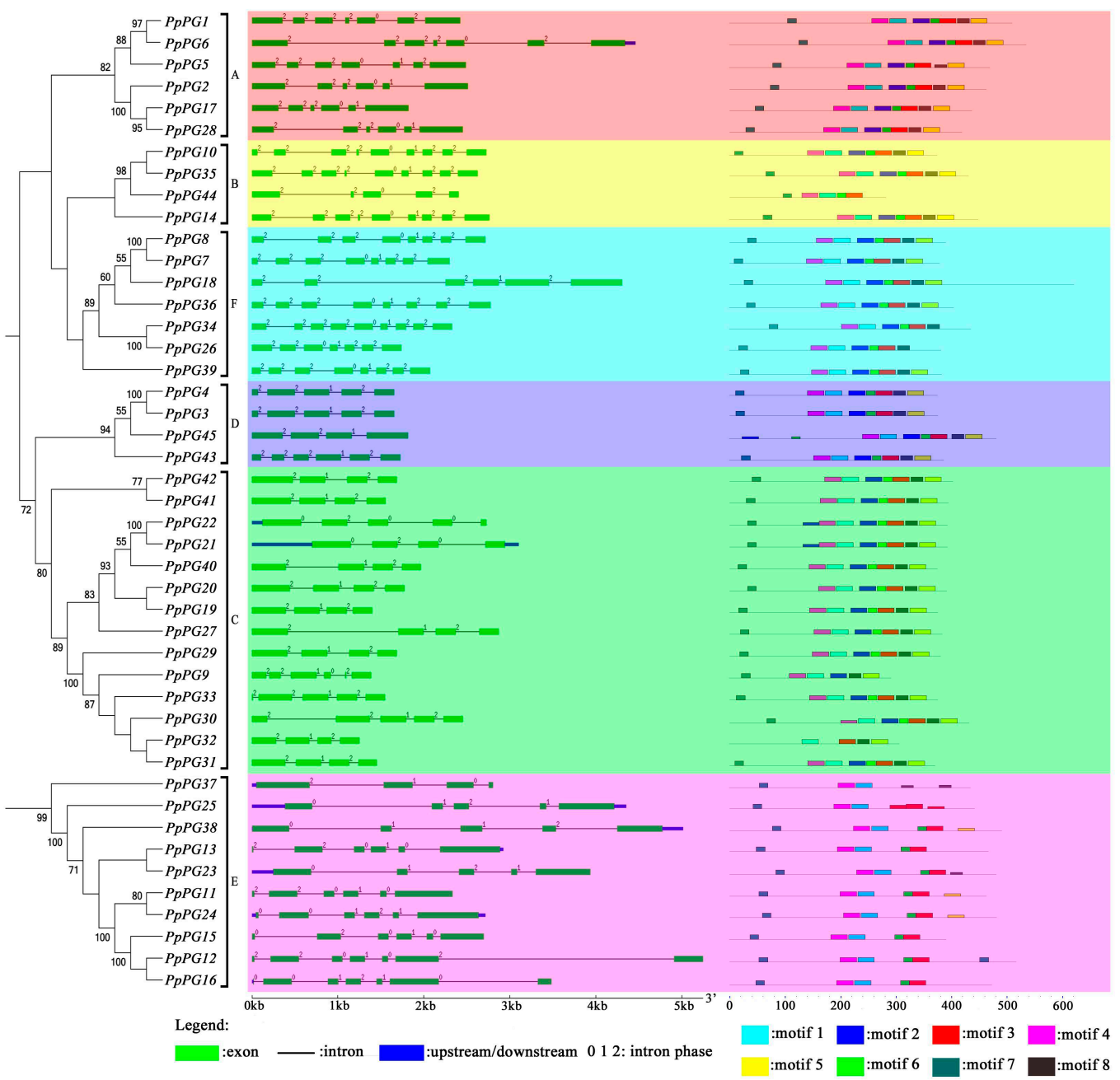

Figure 4. Phylogenetic tree, $P G$ gene structures and conserved motif analysis in peach. The left part indicates the phylogenetic tree of $P G$ genes in peach. Figures on branches indicate bootstrap percentage values calculated from 1000 replicates with MEGA 6.0, and values lower than 50 are hidden in the phylogenetic tree. The middle part represents intron/exon organization of $P G$ genes, and different background colors indicate different subclasses. The right part shows the composition and position of conserved motifs of peach $P G$ genes, with eight motifs shown in different colors. 


\subsection{Fruit Firmness, Ethylene Production and PG Activity Change during Softening}

The two cultivars have different fruit softening characteristics: QJB fruit softening rapidly during ripening, and QW fruits remain firm for a long time during ripening. The firmness, ethylene production, and PG activity in QJB and QW fruits were measured during fruit storage. For QJB fruit, flesh firmness decreased slowly in the first two days after harvest (DAH), and decreased rapidly from two to four $\mathrm{DAH}$, then declined slowly again (Figure 5A). For QW fruit, flesh firmness remained stable for the first $20 \mathrm{DAH}$, and decreased slowly from 20 to $22 \mathrm{DAH}$, then declined dramatically from 22 to $24 \mathrm{DAH}$ (Figure 5B). Ethylene production was very low in QW fruit for the first $22 \mathrm{DAH}$ and then increased markedly from 22 to $24 \mathrm{DAH}$ (Figure 5D). In QJB fruit, ethylene production increased slowly in the first $2 \mathrm{DAH}$, and increased rapidly from two to six DAH, then decreased considerably (Figure 5C).
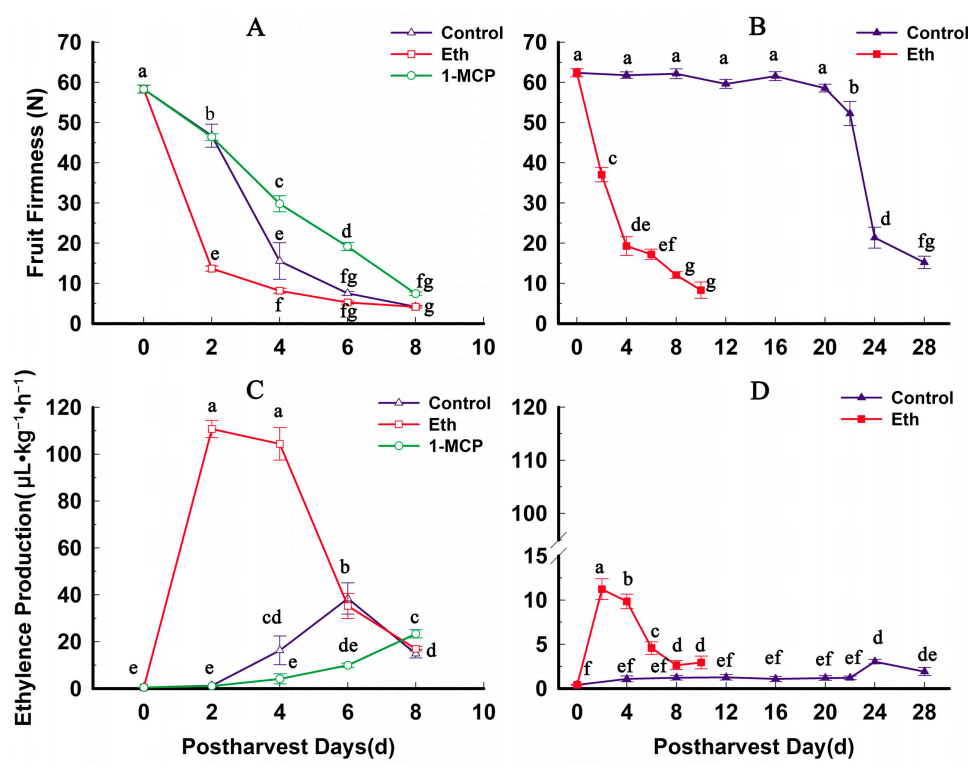

Figure 5. Fruit firmness and ethylene production of control and ethylene-treated fruits during storage in two peach cultivars: (A) “Qian Jian Bai" (QJB) firmness; (B) “Qin Wang” (QW) firmness; (C) QJB ethylene production; and (D) QW ethylene production. Data are the means \pm standard errors $(n=3)$. Significant differences $(p<0.05)$ between means are indicated by different letters.

The activities of exo-PG and endo-PG in the two varieties showed similar trends during storage. In QJB fruit, the activities of exo-PG and endo-PG remained stable for the first two DAH, then increased and reached their maximum activity at $4 \mathrm{DAH}$, and declined from four to six DAH (Figure 6A,C). In QW fruit, the activities of exo-PG and endo-PG also remained at a stable level in the first $20 \mathrm{DAH}$, then increased and reached their maximum activity at $24 \mathrm{DAH}$ and $22 \mathrm{DAH}$, respectively, and then declined (Figure 6B,D). Furthermore, the rate of change of endo-PG activity in QJB fruit was significantly higher than that in QW fruit during storage (Figure 6).
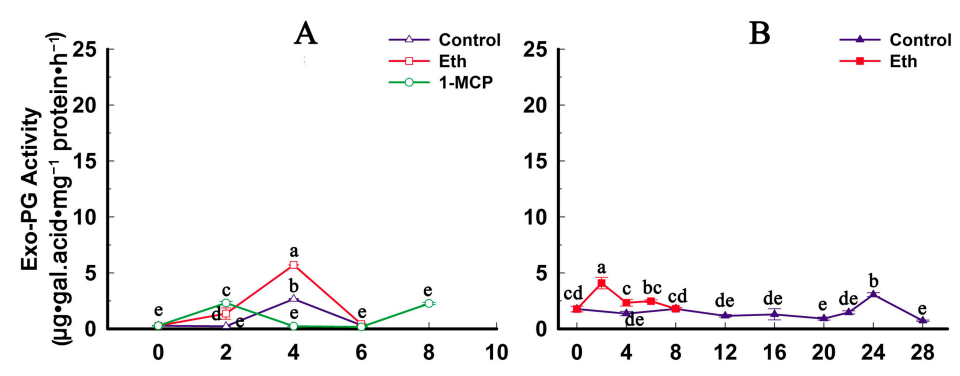

Figure 6. Cont. 

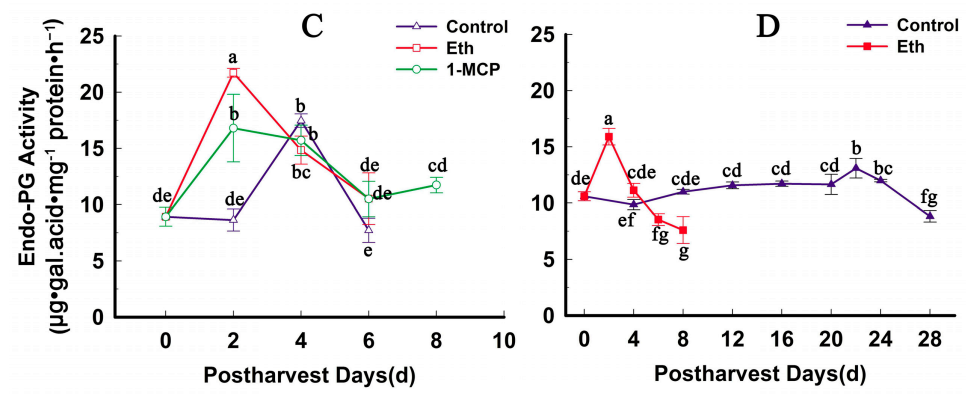

Figure 6. Exo-PG and endo-PG activity of control and ethylene-treated fruits during storage in two peach cultivars: (A) QJB exo-PG activity; (B) QW exo-PG activity; (C) QJB endo-PG activity; and (D) QW endo-PG activity. Data are the means \pm standard errors $(n=3)$. Significant differences $(p<$ 0.05 ) between means are indicated by different letters.

\subsection{Identification of PG Genes Exhibiting Ripening-Associated Patterns of Expression}

We identified the $P G$ genes expressed in fruit by transcriptome sequencing of QJB fruit at the ripening stage, and the results showed that among $45 P p P G$ genes, only 16 were expressed in peach fruit (Table S1). These were PpPG1 and -6 of subclass A; PpPG10, -35 and -14 of subclass B; PpPG21 and -22 of subclass C; PpPG25, $-23,-13,-15,-12,-24,-11$ and -38 of subclass E; and PpPG39 of subclass F. Among these 16 genes, nine (PPPG1, -10,-12,-13,-15, -21,-22, -23 and -25) were up-regulated during softening, three (PpPG11, -14 and -39) were down-regulated, and four ( $P p P G 6,-24,-35$ and -38) were relatively stable (Table $\mathrm{S} 1$ ).

The transcript accumulation patterns of the 16 PPPG genes expressed in peach fruit were assessed in the two varieties by qRT-PCR. The results were consistent with the transcriptome data, and nine PpPG genes (PpPG1, -10,-12,-13,-15, -21,-22,-23 and -25) showed up-regulation, but some differences existed between the two varieties. For QJB fruit, the expression of PpPG1, -10, -12, -21 and -22 was dramatically and continuously increased during the whole storage period, and reached its maximum at the end of storage. PpPG15, -23 and -13 displayed up-regulation for the first four DAH, and then maintained a stable level or declined rapidly. PpPG25 expression remained stable in early storage, and then increased continuously (Figure 7).

Compared with QJB, the expression of PpPG1, -10, -12 and -15 in QW fruit showed a lower level of transcript abundance during the whole storage period, with elevated expression levels only from 22 to 24 DAH. PpPG13 expression was undetectable in QW during the whole storage period. Expression of PpPG21 and -22 remained at a very low level for the first $20 \mathrm{DAH}$, coinciding with the stable firmness. The expression levels subsequently dramatically increased from $20 \mathrm{DAH}$ to 24 or $28 \mathrm{DAH}$. The expression of PpPG23 was maintained stably at a high level during the first $22 \mathrm{DAH}$, increased markedly from 22 to $24 \mathrm{DAH}$, and then decreased rapidly. PpPG25 expression remained relatively stable during storage except at $16 \mathrm{DAH}$ (Figure 7).

During storage, the expression of PpPG11 and -14 exhibited declining trends in the two varieties (Figure 7). PpPG24, -35 and -38 also showed similarity in expression abundance and patterns in the two varieties during storage, and expression of these genes remained relatively stable (Figure 7). $P p P G 6$ and -39 expression was undetectable in the two varieties.

In addition, transcript abundance among the $P G$ genes was significantly different during fruit softening. PpPG1, $-12,-21,-22,-23$ and -11 were the most highly expressed during fruit softening; PpPG10, $-13,-25,-14,-24$ and -38 were moderately expressed; and PpPG15 and -35 showed the lowest level of transcript abundance (Figure 7). 

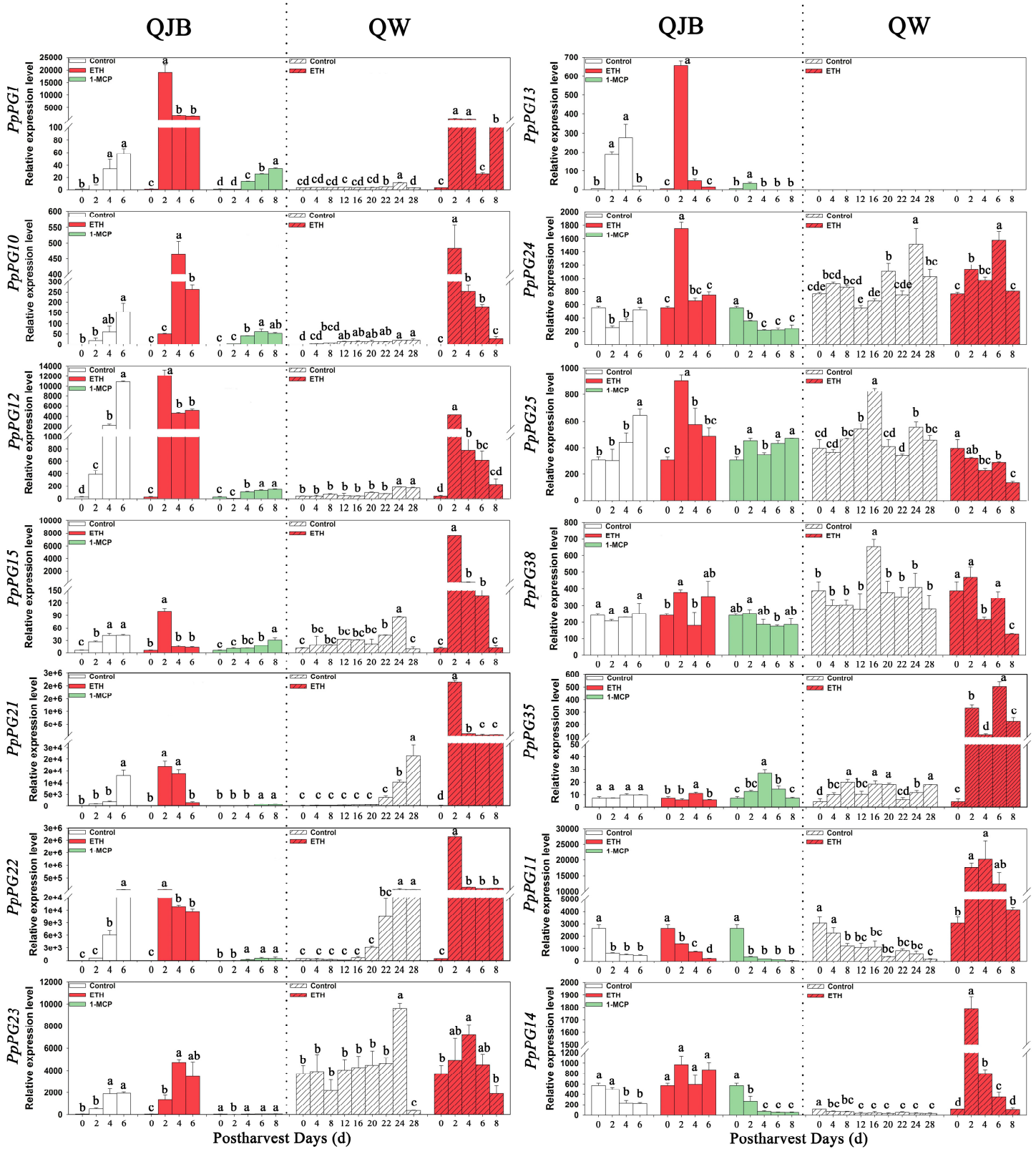

Figure 7. Expression levels of selected $P p P G$ genes in control and ethylene-treated fruits during storage in two peach cultivars. $18 \mathrm{~S}$ served as reference gene. Data are the means \pm standard errors $(n=3)$. Significant differences $(p<0.05)$ between means are indicated by different letters.

\subsection{Ethylene and 1-MCP Alter PG Gene Expression}

To shed more light on the potential role of $P G s$ in fruit ripening, we compared their expression under ethylene and/or 1-MCP treatment during storage. After ethylene treatment, the changes in firmness and ethylene release in the two varieties were very similar. The decrease in fruit firmness was faster than that in the control fruit, especially in the first two DAH. At the same time, after ethylene treatment, the rate of ethylene release increased sharply and peaked at two DAH, with higher peak rates for treated fruit than for controls (Figure 5). Furthermore, in QJB fruit, after ethylene treatment, the expression of eight PpPG genes (PpPG1, -12, -13,-15, -21, -22, -24 and -25) also dramatically increased and peaked at two DAH, with higher peak expression for treated fruit than for controls (Figure 7). The expression of PpPG10 and -23 was also significantly increased by ethylene treatment, 
and peaked at four DAH. Compared with the control, ethylene treatment had little effect on the expression of $P p P G 11,-14,-35$ and -38. For slow-ripening QW fruit, after ethylene treatment, the expression of seven PpPG genes (PpPG1,-10,-12,-14,-15,-21 and -22) increased dramatically and peaked at two DAH, with higher peak expression for treated fruit than for controls (Figure 7). Ethylene treatment also significantly enhanced the expression levels of PpPG11 and -35, and had little effect on the expression of PpPG13, -23, -24, -25, and -38 (Figure 7).

After treatment with 1-MCP, the expression levels of eight PpPG genes (PpPG1, -10, -12, -15, $-21,-22,-23$ and -13 ) were significantly inhibited in QJB fruit during the whole storage period, with especially obvious declines observed for PpPG12, -21, -22 and -23. However, expression of PpPG25, -11, $-14,-24,-35$ and -38 was little affected by $1-\mathrm{MCP}$ treatment (Figure 7).

\section{Discussion}

\subsection{PG Family Member Identification and Sequence Analysis}

PG is a cell wall hydrolytic enzyme with important roles in many physiological processes, such as fruit ripening, seed germination, cell elongation, organ abscission and pollen tube elongation $[4,12,14,20,26,30,38]$. $P G$ s are encoded by a typical large gene family in plants, and the $P G$ gene family has been identified and characterized in some plants such as Arabidopsis, Populus, rice, Cucumis sativus and Citrullus lanatus [29,31-33]. In this study, we identified $45 P G$ genes in the peach genome, and Arabidopsis, Populus, Cucumis sativus and Citrullus lanatus have 68, 75, 53 and 62 PG genes, respectively. Peach has fewer $P G$ members than the above species, and this may be because peach has not undergone recent whole-genome duplication [39] and the expansion of subclasses is different in different plants.

Most $P G$ members from various species contain four conserved domains [33,40]. Domains I and II are likely to compose the catalytic site, domain III can take part in catalytic reactions, and domain IV constitutes a likely candidate for ionic interactions with carboxylate groups present in the substrate [41]. The peach PG genes of subclasses A, B, C, D and F contain the four conserved domains and seven to nine motifs, but $P G$ members of subclass $E$ lack domain III and contain five or six motifs (Table 1, Figure 4). Other studies in plants have also shown that domain III of PGs in subclass E is not conserved $[33,40]$. Our results showed that most peach $P G$ genes of subclass $E$ are expressed in the ripening fruit (Figure 2), which is similar to the results in Arabidopsis [31]. In addition, the involvement of $P G$ genes of E subclass in fruit abscission was also observed in lychee and Elaeis guineensis [26,42] Therefore, most fruit related $P G$ genes may belongs to E subclass, which may be related to their conserved functions in fruit abscission and/or ripening. Except for very low expression of $P p P G 39$, peach $P G$ genes of subclasses $\mathrm{D}$ and $\mathrm{F}$ are not expressed in ripening fruit, which suggests that these $P G$ genes cannot be involved in peach fruit softening during ripening. In addition, $P p P G 7,-8,-18,-26$, $-34,-36$ in subclass $F$ formed a special sub-clades without other species members, and had the low bootstrap support $(<50 \%)$, which suggesting these PG members may be peach-special. Subclass $C$ contained 14 peach $P G$ members; however, only $P p P G 21$ and -22 were expressed in the ripening fruit. PpPG21 and -22 are 100\% similar to PdPG1 (ABD33834), which involved in the regulation of seed maturation and drying, fruit ripening in damson plum [43]. In addition, tomato TAPG1, $-2,-4$, and -5 in subclass C were associated with fruit abscission [44,45]. Similarly, Monocot oil palm EgPG4 gene in subclass $C$ participated in cell wall pectin modifications as well during both mesocarp ripening and fruit shedding [42]. These studies suggested that PpPG21 and -22 are probably related to peach fruit ripening and abscission. Two tomato fruit ripening related PG genes (AAA34178, and NP_001234021) were classified into Subclass B [46,47], together with other fruit ripening related $P G$ genes (such as, $V v P G 1$ in grape and ZMdPG1 in apple) [48,49]. Meanwhile, in Arabidopsis, ADPG1 and -2 in subclass B had been reported to be essential for silique dehiscence, and ADPG2 and QRT2 contribute to floral organ abscission [30]. Our results also showed that PpPG10, -14, and -35 in group B were expressed in mature fruit, suggesting these PGs may be associated with peach fruit ripening. 


\subsection{Possible Roles of PG Family Members in Fruit Softening during Ripening}

The role of PG in fruit softening has been studied extensively, and an increase in PG activity and mRNA levels has been observed during ripening in several fruits $[4,11,15-17,20,50]$. PG hydrolyzes pectin acid along with the its main chain, causing pectin degradation, cell wall dissolution, and ultimately, fruit softening [51]. However, as a multi-gene family, $P G$ members were expressed at different stages and in different tissues during the development of plants [31]. Thus far, little is known about the role of $P G$ family members in fruit softening. Pan et al. (2015) indicated that PpPG21 (ppa006839) and -22 (ppa006857) were relatively highly expressed in ripening peach fruit, but that their transcripts were almost undetectable in fruit during development [52]. Gu et al. (2016) also demonstrated that PpPG22 and -21 are responsible for stone adhesion and melting flesh, respectively [25]. The mRNA levels of PpPG1 (ppa018113) were lower in both the melting type and the stony hard type peach, although they increased slightly after ethylene treatment in the stony hard type peach [36].

Based on the expression profiles of 16 P P P genes during fruit softening and under the treatments of ethylene and/or 1-MCP, a small subset of $P G$ genes highly linked to the softening process was identified. In natural ripening fruit of QJB, nine PGs (PpPG1, -10, -12, -13, -15, -23, -21, -22 and -25) exhibited softening-associated patterns and up-regulated expression during storage. Among these, eight $P G s$ (all except $P p P G 25$ ), which displayed dramatic up-regulation after ethylene treatment and significant down-regulation after 1-MCP treatment (Figure 7), emerge as strong candidates to play a role in QJB fruit softening. However, in natural slowly-softening QW fruit, only PpPG15, -21 and -22 expression showed softening-associated patterns during storage, and also displayed dramatic up-regulation after ethylene treatment (Figure 7), which indicated that $P p P G 15,-21$ and -22 play a role in QW fruit softening. Thus, as common candidate genes in two varieties, PpPG15, -21 and -22 may play major roles in peach fruit softening. Moreover, the number of $P G$ family members were involved in fruit softening was different in cultivars having different softening characteristics. More $P G$ members play a role in fast softening peach varieties, and fewer $P G$ members are active in slow-softening peach fruit.

Ethylene has been assigned a major role in the ripening of climacteric fruits, controlling the transcription of softening-related genes [53]. Hiwasa et al. (2003) reported that ethylene is required for $P G$ expression even in the late ripening stage [15]. A stony hard type peach fruit characterized by a lack of ethylene production and firm flesh in the mature fruit retained low PpPG mRNA expression and endoPG enzyme activity during storage. Ethylene treatment resulted in stony hard type peach fruit softening rapidly and increasing $P p P G$ mRNA expression and endo-PG enzyme activity [54,55]. Our results also showed that endo-PG and exo-PG enzyme activity and expression of most $P G$ members is induced by exogenous ethylene treatment, but there are differences between two cultivars. PpPG11, -14 and -35 showed down-regulated or stable expression in naturally ripening QJB and QW fruit during storage, and their expression was not affected by ethylene treatment during QJB storage. However, in QW fruit, the expression of PpPG11, -14 and -35 increased sharply after ethylene treatment (Figure 7), which suggests that PPPG11, -14 and -35 do not play a role in softening of QJB fruit, but participate in ethylene-induced ripening and softening in QW fruit.

In addition, the expression of PPPG1, -10 and -12 remained at a lower level in QW fruit during natural ripening, but increased dramatically throughout the storage period when treated with ethylene. This was accompanied by a rapid increase in ethylene evolution (Figure 7), which suggests that PpPG1, -10 and -12 rarely affect normal softening of QW peach fruit, but when stimulated with ethylene, their expression levels rapidly increase and accelerate the softening of QW peach fruit. The expression levels of PpPG24, -25 and -38 were high and stable during the whole storage period, and were hardly affected by ethylene treatment in either QW or QJB variety fruit (Figure 7), which suggests that the expression of these $P G s$ is not regulated by ethylene, and not related to peach fruit softening. 


\section{Materials and Methods}

\subsection{Plant Materials and Treatment}

Peach fruit (Prunus persica L. Batsch cv. "Qian jian bai" (QJB) and "Qin wang" (QW)) from the Experimental Station of the College of Horticulture, Northwest A\&F University in Yangling, Shaanxi, China, were used in this study. In our experiment, flesh texture trait of QW, whose phenotype resembles very much the stony hard type flesh in firmness and crispness, but when fully ripe becomes melting and releases ethylene. This flesh texture trait results in remarkable keeping quality, particularly on the tree, and is rewarding for growers, consumers and researchers [56].

Fruit with no visible defects were harvested when they were commercially mature (fading peel color that is light green, partially red; slightly hard flesh). For QJB, all of the intact fruit were divided randomly into three groups. One group was soaked in $1 \mathrm{~g} / \mathrm{L}$ ethephon for $15 \mathrm{~min}$ at $25 \pm 1{ }^{\circ} \mathrm{C}$. The second group was treated with $5 \mu \mathrm{L} / \mathrm{L}$ 1-methylcyclopropene (1-MCP) for $24 \mathrm{~h}$ in a closed container, and the third group was soaked in water for $15 \mathrm{~min}$ and served as the control group. For QW, fruit were divided into two groups. One group was soaked in $1 \mathrm{~g} / \mathrm{L}$ ethephon for $15 \mathrm{~min}$ at $25 \pm 1{ }^{\circ} \mathrm{C}$. The other group was soaked in water and served as the control group. Each group consisted of 150 fruit, which were stored at $25^{\circ} \mathrm{C}$. Samples were taken every other day until the flesh fully softened. All samples were frozen with liquid nitrogen and stored at $-80{ }^{\circ} \mathrm{C}$.

\subsection{RNA Extraction and Reverse Transcription}

Total RNA was extracted according to the protocol described by Lester et al. (1994) [35]. RNA integrity and quality were tested using an ultraviolet spectrophotometer (Thermo NanoDrop 2000, Wilmington, DE, USA) and electrophoresis in 1\% agarose gels, respectively. Reverse transcription was completed using the PrimeScript RT Reagent Kit with gDNA Eraser (Takara, Beijing, China).

\subsection{Identification of Peach PG Family Members}

All members of the peach $P G$ family were identified using two steps. First, hidden Markov model (HMM) profiles of the PG domain (Accession No. PF00295) were retrieved from the Pfam database [57]. Second, these domains and identified Arabidopsis PG sequences [12] were used as queries to search the GenBank non-redundant protein database and the Peach Genome Database [58]. Then all of the candidate peach PG family members were submitted to SMART [59] and Pfam to determine the presence of the domain. Those candidate PG family members that contained at least two highly conserved domains (of domains I, II, III, and IV) of PGs [60], were considered to be PGs.

\subsection{Multiple Sequence Alignment, Phylogenetic Analysis, Exon/Intron Structure Determination and Chromosome Locations}

Multiple sequence alignment was performed and conserved domains were analyzed using DNAMAN 6.0 with default settings. A phylogenetic tree was generated with MEGA 6.0 using the neighbor-joining (NJ) method, and edge support was estimated using 1000 bootstrap replicates. Exon/intron structure was generated with the online software GSDS [61]. Consensus sequence graphs were obtained with the online software WebLogo [62]. Signal peptides were analyzed using SignalP v3.0 [63]. Molecular weights and pIs of the proteins were calculated with the ExPASY Compute $\mathrm{pI} / \mathrm{M}_{\mathrm{W}}$ tool [64]. To identify conserved motifs within the PG genes, MEME [65] motif analysis was performed. For chromosome locations, data were downloaded from NCBI [66] and genes were mapped to the chromosomes with MapDraw [67].

\subsection{RNA Deep Sequencing and Library Construction}

The QJB fruits from 0, 2, and 4 days after harvest were selected to extracted RNA. The quantity and quality of extracted RNA were tested using using a NanoDrop ND1000 spectro-photometer (Thermo NanoDrop 2000, Wilmington, DE, USA) and electrophoresis in 1\% agarose gels, respectively. 
A 2- $\mu$ g total RNA from each sample was used for constructing cDNA libraries and they were sequenced using an Illumina HiSeq ${ }^{\mathrm{TM}} 2000$ by the Biomarker Biotechnology Corporation (Beijing, China). The experiment was repeated three times. The detailed methods of raw fastq files handling from RNA-seq were carried out according to Xing [68].

\subsection{Real-Time Quantitative PCR ( $q P C R$ ) Assays}

Real-time quantitative PCR (qPCR) was performed using an iQ5 real-time PCR system (BioRad, Plano, TX, USA). Gene-specific primers were designed using Beacon Designer 8.0 (Table S2). For each sample, $1 \mu \mathrm{L}$ cDNA, $1 \mu \mathrm{L}$ of each primer, $2 \mu \mathrm{L}$ dd $_{2} \mathrm{O}$ and $5 \mu \mathrm{L}$ of $2 \times$ SYBR Premix ExTaq II (TaKaRa, Dalian, China) were used for qPCR in a total volume of $10 \mu \mathrm{L}$. The qPCR protocol was as specified for the SYBR Premix Ex Taq kit, $1 \mathrm{~min}$ at $95^{\circ} \mathrm{C}$, followed by 40 cycles of $15 \mathrm{~s}$ at $95^{\circ} \mathrm{C}, 20 \mathrm{~s}$ at annealing temperature and $20 \mathrm{~s}$ at $72{ }^{\circ} \mathrm{C}$, followed by $10 \mathrm{~s}$ at $95^{\circ} \mathrm{C}$, followed by 40 cycles to construct a melting curve. Peach $18 \mathrm{~S}$ ribosomal RNA (18S rRNA) was selected as the reference gene. Relative expression level data were analyzed using the $2^{-\Delta \Delta C t}$ method [69]. Each sample was analyzed in triplicate.

\subsection{Flesh Firmness, Ethylene Production and Determination of Enzyme Activity}

Firmness was measured using the GY-4 firmness meter (Top instrument Co., Ltd., Hangzhou, China) equipped with a 7.9-mm probe. In each group, six fruit were randomly selected and a small piece of epicarp was peeled off from two symmetrical positions on each fruit to attach the probe. Ethylene production was determined as described by Liguori et al. (2004) [70]. Nine fruit were weighed and sealed in a jar for $1 \mathrm{~h}$. An air sample $(1 \mathrm{~mL})$ from the jar was analyzed using a gas chromatograph (Trace GC Ultra, Thermo Fisher, New York, NY, USA). The activities of exo-PG and endo-PG were measured according to Cao et al. (2014) [71].

\subsection{Statistical Analysis}

Microsoft Excel 2010 and DPS v7.05 were used for data processing and correlation analysis, and SigmaPlot 10.0 was used to prepare figures.

\section{Conclusions}

In conclusion, a genome-wide analysis of $P G$ gene family in peach was performed to reveal gene structure, phylogenetic relationship, and expression profiles during fruit softening. During the normal ripening, eight PGs (PpPG1, -10, -12, -13,-15, -23, -21, and -22) in fast-softening QJB fruit and three PGs (PpPG15, -21, and -22) in slow-softening QW fruit exhibited softening-associated patterns, which were also affected by ethylene treatment. Our results suggest that the different softening characters in QW and QJB fruit are related to the amount of PG members.

Supplementary Materials: Supplementary materials can be found at www.mdpi.com/1422-0067/17/11/1933/s1.

Acknowledgments: We want to thank Lijun Cao for bioinformatics guidance; Liwei Zheng for qPCR instructions; BaoJuan Zhang for enzymatic activity assistance; and Lei Zhao for providing selfless assistance providing. In addition, we still wish to express our thanks to Minghui Lu English language correction. This study was supported by grants from National Science Foundation of China (Grant No. 31572079), the Natural Science Foundation of Shaanxi Province, China (Grant No. 2015JM3103), and the Science and Technology Co-ordination \& Innovation Foundation of Shaanxi Province, China (Grant No. 2015KTCQ02-23).

Author Contributions: Caiping Zhao, Mingyu Han and Dong Zhang designed experiments. Ming Qian, Yike Zhang, Xiangyan Yan, and Furui Li performed all biochemical and plant physiological experiments. Ming Qian, Jinjin Li and Fang Li analyzed all data. Caiping Zhao and Ming Qian wrote the manuscript.

Conflicts of Interest: The authors declare no conflict of interest. 


\section{References}

1. Barry, C.S.; Giovannoni, J.J. Ethylene and fruit ripening. J. Plant Growth Regul. 2007, 26, 143-159. [CrossRef]

2. Osorio, S.; Scossa, F.; Fernie, A.R. Molecular regulation of fruit ripening. Front. Plant Sci. 2013, 4, 198. [CrossRef] [PubMed]

3. Yoshioka, H.; Hayama, H.; Tatsuki, M.; Nakamura, Y. Cell wall modification during development of mealy texture in the stony-hard peach "odoroki" treated with propylene. Postharvest Biol. Technol. 2010, 55, 1-7. [CrossRef]

4. Brummell, D.A.; Dal Cin, V.; Crisosto, C.H.; Labavitch, J.M. Cell wall metabolism during maturation, ripening and senescence of peach fruit. J. Exp. Bot. 2004, 55, 2029-2039. [CrossRef] [PubMed]

5. Carpita, N.C.; Gibeaut, D.M. Structural models of primary cell walls in flowering plants: Consistency of molecular structure with the physical properties of the walls during growth. Plant J. 1993, 3, 1-30. [CrossRef] [PubMed]

6. Yin, Y.; Chen, H.; Hahn, M.G.; Mohnen, D.; Xu, Y. Evolution and function of the plant cell wall synthesis-related glycosyltransferase family 8. Plant Physiol. 2010, 153, 1729-1746. [CrossRef] [PubMed]

7. Caffall, K.H.; Mohnen, D. The structure, function, and biosynthesis of plant cell wall pectic polysaccharides. Carbohydr. Res. 2009, 344, 1879-1900. [CrossRef] [PubMed]

8. Jarvis, M.C.; Briggs, S.P.H.; Knox, J.P. Intercellular adhesion and cell separation in plants. Plant Cell Environ. 2003, 26, 977-989. [CrossRef]

9. Fry, S.C. The Growing Plant Cell Wall: Chemical and Metabolic Analysis; John Wiley \& Sons: New York, NY, USA, 1988; pp. 332-365.

10. Habibi, Y.; Heyraud, A.; Mahrouz, M.; Vignon, M.R. Structural features of pectic polysaccharides from the skin of opuntia ficus-indica prickly pear fruits. Carbohydr. Res. 2004, 339, 1119-1127. [CrossRef] [PubMed]

11. Hadfield, K.A.; Bennett, A.B. Polygalacturonases: Many genes in search of a function. Plant Physiol. 1998, 117, 337-343. [CrossRef] [PubMed]

12. Gonzalez-Carranza, Z.H.; Elliott, K.A.; Roberts, J.A. Expression of polygalacturonases and evidence to support their role during cell separation processes in arabidopsis thaliana. J. Exp. Bot. 2007, 58, 3719-3730. [CrossRef] [PubMed]

13. Atkinson, R.G.; Schröder, R.; Hallett, I.C.; Cohen, D.; MacRae, E.A. Overexpression of polygalacturonase in transgenic apple trees leads to a range of novel phenotypes involving changes in cell adhesion. Plant Physiol. 2002, 129, 122-133. [CrossRef] [PubMed]

14. Pose, S.; Paniagua, C.; Cifuentes, M.; Blanco-Portales, R.; Quesada, M.A.; Mercado, J.A. Insights into the effects of polygalacturonase FaPG1 gene silencing on pectin matrix disassembly, enhanced tissue integrity, and firmness in ripe strawberry fruits. J. Exp. Bot. 2013, 64, 3803-3815. [CrossRef] [PubMed]

15. Hiwasa, K.; Kinugasa, Y.; Amano, S.; Hashimoto, A.; Nakano, R.; Inaba, A.; Kubo, Y. Ethylene is required for both the initiation and progression of softening in pear. J. Exp. Bot. 2003, 54, 771-779. [CrossRef] [PubMed]

16. Asif, M.H.; Nath, P. Expression of multiple forms of polygalacturonase gene during ripening in banana fruit. Plant Physiol. Biochem. 2005, 43, 177-184. [CrossRef] [PubMed]

17. Fabi, J.P.; Cordenunsi, B.R.; Seymour, G.B.; Lajolo, F.M.; do Nascimento, J.R. Molecular cloning and characterization of a ripening-induced polygalacturonase related to papaya fruit softening. Plant Physiol. Biochem. 2009, 47, 1075-1081. [CrossRef] [PubMed]

18. Abu-Goukh, A.-B.A.; Bashir, H.A. Changes in pectic enzymes and cellulase activity during guava fruit ripening. Food Chem. 2003, 83, 213-218. [CrossRef]

19. Rao, G.U.; Paran, I. Polygalacturonase: A candidate gene for the soft flesh and deciduous fruit mutation in capsicum. Plant Mol. Biol. 2003, 51, 135-141. [PubMed]

20. Costa, F.; Peace, C.P.; Stella, S.; Serra, S.; Musacchi, S.; Bazzani, M.; Sansavini, S.; Van de Weg, W.E. QTL dynamics for fruit firmness and softening around an ethylene-dependent polygalacturonase gene in apple (malus x domestica borkh.). J. Exp. Bot. 2010, 61, 3029-3039. [CrossRef] [PubMed]

21. Smith, C.J.S.; Watson, C.F.; Ray, J.; Bird, C.R.; Morris, P.C.; Schuch, W.; Grierson, D. Antisense rna inhibition of polygalacturonase gene expression in transgenic tomatoes. Nature 1988, 334, 724-726. [CrossRef]

22. Callahan, A.M.; Scorza, R.; Bassett, C.; Nickerson, M.; Abeles, F.B. Deletions in an endopolygalacturonase gene cluster correlate with non-melting flesh texture in peach. Funct. Plant Biol. 2004, 31, 159-168. [CrossRef] 
23. Ghiani, A.; Onelli, E.; Aina, R.; Cocucci, M.; Citterio, S. A comparative study of melting and non-melting flesh peach cultivars reveals that during fruit ripening endo-polygalacturonase (endo-PG) is mainly involved in pericarp textural changes, not in firmness reduction. J. Exp. Bot. 2011, 62, 4043-4054. [CrossRef] [PubMed]

24. Peace, C.P.; Crisosto, C.H.; Gradziel, T.M. Endopolygalacturonase: A candidate gene for freestone and melting fleshin peach. Mol. Breed. 2005, 16, 21-31. [CrossRef]

25. Gu, C.; Wang, L.; Wang, W.; Zhou, H.; Ma, B.; Zheng, H.; Fang, T.; Ogutu, C.; Vimolmangkang, S.; Han, Y. Copy number variation of a gene cluster encoding endopolygalacturonase mediates flesh texture and stone adhesion in peach. J. Exp. Bot. 2016, 67, 1993-2005. [CrossRef] [PubMed]

26. Peng, G.; Wu, J.; Lu, W.; Li, J. A polygalacturonase gene clustered into clade e involved in lychee fruitlet abscission. Sci. Hortic. 2013, 150, 244-250. [CrossRef]

27. González-Carranza, Z.H.; Whitelaw, C.A.; Swarup, R.; Roberts, J.A. Temporal and spatial expression of a polygalacturonase during leaf and flower abscission in oilseed rape and arabidopsis. Plant Physiol. 2002, 128, 534-543. [CrossRef] [PubMed]

28. Jiang, C.-Z.; Lu, F.; Imsabai, W.; Meir, S.; Reid, M.S. Silencing polygalacturonase expression inhibits tomato petiole abscission. J. Exp. Bot. 2008, 59, 973-979. [CrossRef] [PubMed]

29. Rhee, S.Y.; Somerville, C.R. Tetrad pollen formation in quartet mutants of arabidopsis thaliana is associated with persistence of pectic polysaccharides of the pollen mother cell wall. Plant J. 1998, 15, 79-88. [CrossRef] [PubMed]

30. Ogawa, M.; Kay, P.; Wilson, S.; Swain, S.M. Arabidopsis Dehiscence zone Polygalacturonase1 (ADPG1), ADPG2, and QUARTET2 are Polygalacturonases required for cell separation during reproductive development in arabidopsis. Plant Cell 2009, 21, 216-233. [CrossRef] [PubMed]

31. Kim, J.; Shiu, S.-H.; Thoma, S.; Li, W.-H.; Patterson, S.E. Patterns of expansion and expression divergence in the plant polygalacturonase gene family. Genome Biol. 2006, 7, R87. [CrossRef] [PubMed]

32. Yang, Z.L.; Liu, H.J.; Wang, X.R.; Zeng, Q.Y. Molecular evolution and expression divergence of the populus polygalacturonase supergene family shed light on the evolution of increasingly complex organs in plants. New Phytol. 2013, 197, 1353-1365. [CrossRef] [PubMed]

33. Yu, Y.; Liang, Y.; Lv, M.; Wu, J.; Lu, G.; Cao, J. Genome-wide identification and characterization of polygalacturonase genes in cucumis sativus and citrullus lanatus. Plant Physiol. Biochem. 2014, 74, $263-275$. [CrossRef] [PubMed]

34. Morgutti, S.; Negrini, N.; Nocito, F.F.; Ghiani, A.; Bassi, D.; Cocucci, M. Changes in endopolygalacturonase levels and characterization of a putative endo-PG gene during fruit softening in peach genotypes with nonmelting and melting flesh fruit phenotypes. New Phytol. 2006, 171, 315-328. [CrossRef] [PubMed]

35. Lester, D.R.; Speirs, J.; Orr, G.; Brady, C.J. Endopolygalacturonase cdna isolation and its expression analysis in melting and nonmelting peach cultivars. Plant Physiol. 1994, 105, 225-231. [CrossRef] [PubMed]

36. Murayama, H.; Arikawa, M.; Sasaki, Y.; dal Cin, V.; Mitsuhashi, W.; Toyomasu, T. Effect of ethylene treatment on expression of polyuronide-modifying genes and solubilization of polyuronides during ripening in two peach cultivars having different softening characteristics. Postharvest Biol. Technol. 2009, 52, 196-201. [CrossRef]

37. Rhee, S.Y.; Osborne, E.; Poindexter, P.D.; Somerville, C.R. Microspore separation in the QUARTET3 mutants of arabidopsis is impaired by a defect in a developmentally regulated polygalacturonase required for pollen mother cell wall degradation. Plant Physiol. 2003, 133, 1170-1180. [CrossRef] [PubMed]

38. Sitrit, Y.; Hadfield, K.A.; Bennett, A.B.; Bradford, K.J.; Downie, A.B. Expression of a polygalacturonase associated with tomato seed germination. Plant Physiol. 1999, 121, 419-428. [CrossRef] [PubMed]

39. Initiative, T.I.P.G.; Verde, I.; Abbott, A.G.; Scalabrin, S.; Jung, S.; Shu, S.; Marroni, F.; Zhebentyayeva, T.; Dettori, M.T.; Grimwood, J.; et al. The high-quality draft genome of peach (Prunus persica) identifies unique patterns of genetic diversity, domestication and genome evolution. Nat. Genet. 2013, 45, 487-494.

40. Park, K.C.; Kwon, S.J.; Kim, P.H.; Bureau, T.; Kim, N.S. Gene structure dynamics and divergence of the polygalacturonase gene family of plants and fungus. Genome 2008, 51, 30-40. [PubMed]

41. Stratilová, E.; Mislovičová, D.; Kačuráková, M.; Machová, E.; Kolarová, N.; Markovič, O.; Jörnvall, H. The glycoprotein character of multiple forms of aspergillus polygalacturonase. J. Protein Chem. 1998, 17, 173-179. [CrossRef] [PubMed] 
42. Roongsattham, P.; Morcillo, F.; Jantasuriyarat, C.; Pizot, M.; Moussu, S.; Jayaweera, D.; Collin, M.; Gonzalez-Carranza, Z.H.; Amblard, P.; Tregear, J.W.; et al. Temporal and spatial expression of polygalacturonase gene family members reveals divergent regulation during fleshy fruit ripening and abscission in the monocot species oil palm. BMC Plant Biol. 2012, 12, 150. [CrossRef] [PubMed]

43. Iglesias-Fernándeza, R.; Matilla, A.J.; Rodríguez-Gacio, M.C.; Fernández-Otero, C.; Torre, F.D.L. The polygalacturonase gene PdPG1 is developmentally regulated in reproductive organs of Prunus domestica L. Subsp. insititia. Plant Sci. 2007, 172, 763-772. [CrossRef]

44. Kalaitzis, P.; Koehler, S.M.; Tucker, M.L. Cloning of a tomato polygalacturonase expressed in abscission. Plant Mol. Biol. 1995, 28, 647-656. [CrossRef] [PubMed]

45. Kalaitzis, P.; Solomos, T.; Tucker, M.L. Three different polygalacturonases are expressed in tomato leaf and flower abscission, each with a different temporal expression pattern. Plant Physiol. 1997, 113, 1303-1308. [CrossRef] [PubMed]

46. Bird, C.R.; Smith, C.J.S.; Ray, J.A.; Moureau, P.; Bevan, M.W.; Bird, A.S.; Hughes, S.; Morris, P.C.; Grierson, D.; Schuch, W. The tomato polygalacturonase gene and ripening-specific expression in transgenic plants. Plant Mol. Biol. 1988, 11, 651-662. [CrossRef] [PubMed]

47. DellaPenna, D.; Bennett, A.B. In vitro synthesis and processing of tomato fruit polygalacturonase. Plant Physiol. 1988, 86, 1057-1063. [CrossRef] [PubMed]

48. Deytieux-Belleau, C.; Vallet, A.; Doneche, B.; Geny, L. Pectin methylesterase and polygalacturonase in the developing grape skin. Plant Physiol. Biochem. 2008, 46, 638-646. [CrossRef] [PubMed]

49. Li, M.; Zhang, Y.; Zhang, Z.; Ji, X.; Zhang, R.; Liu, D.; Gao, L.; Zhang, J.; Wang, B.; Wu, Y.; et al. Hypersensitive ethylene signaling and zmdpg1 expression lead to fruit softening and dehiscence. PLoS ONE 2013, 8, e58745. [CrossRef] [PubMed]

50. Chen, H.; Cao, S.; Fang, X.; Mu, H.; Yang, H.; Wang, X.; Xu, Q.; Gao, H. Changes in fruit firmness, cell wall composition and cell wall degrading enzymes in postharvest blueberries during storage. Sci. Hortic. 2015, 188, 44-48. [CrossRef]

51. Wei, J.; Ma, F.; Shi, S.; Qi, X.; Zhu, X.; Yuan, J. Changes and postharvest regulationof activity and gene expression of enzymes related to cell wall degradation inripening apple fruit. Postharvest Biol. Technol. 2010, 56, 147-154. [CrossRef]

52. Pan, L.; Zeng, W.; Niu, L.; Lu, Z.; Liu, H.; Cui, G.; Zhu, Y.; Chu, J.; Li, W.; Fang, W.; et al. PpYUC11, a strong candidate gene for the stony hard phenotype in peach (Prunus persica L. Batsch), participates in IAA biosynthesis during fruit ripening. J. Exp. Bot. 2015, 66, 7031-7044. [CrossRef] [PubMed]

53. Bapat, V.A.; Trivedi, P.K.; Ghosh, A.; Sane, V.A.; Ganapathi, T.R.; Nath, P. Ripening of fleshy fruit: Molecular insight and the role of ethylene. Biotechnol. Adv. 2010, 28, 94-107. [CrossRef] [PubMed]

54. Hayama, H.; Shimada, T.; Fujii, H.; Ito, A.; Kashimura, Y. Ethylene-regulation of fruit softening and softening-related genes in peach. J. Exp. Bot. 2006, 57, 4071-4077. [CrossRef] [PubMed]

55. Hayama, H.; Tatsuki, M.; Ito, A.; Kashimura, Y. Ethylene and fruit softening in the stony hard mutation in peach. Postharvest Biol. Technol. 2006, 41, 16-21. [CrossRef]

56. Layne, D.R.; Bassi, D. The Peach: Botany, Production and Uses; CABI: Oxfordshire, UK, 2008.

57. Pfam. Avaliable online: http://pfam.Sanger.Ac.Uk/ (accessed on 9 September 2016).

58. Database, P.G. Available online: https://www.Rosaceae.Org/species/prunus_persica/genome_v2.0.A1 (accessed on 9 September 2016).

59. SMART. Available online: http://smart.Embl-heidelberg.De/ (accessed on 9 September 2016).

60. Torki, M.; Mandaron, P.; Mache, R.; Falconet, D. Characterization of a ubiquitous expressed gene family encoding polygalacturonase in arabidopsis thaliana. Gene 2000, 242, 427-436. [CrossRef]

61. GSDS. Avaliable online: http://gsds.Cbi.Pku.Edu.Cn/ (accessed on 9 September 2016).

62. WebLogo. Avaliable online: http://weblogo.Berkeley.Edu/logo.Cgi (accessed on 9 September 2016).

63. V3.0, S. Avaliable online: http://www.Cbs.Dtu.Dk/services/signalp (accessed on 9 September 2016).

64. ExPASY. Avaliable online: http://www.Expasy.Org/tool.Html (accessed on 9 September 2016).

65. MEME. Avaliable online: http://meme.Nbcr.Net/meme/cgi-bin/meme.Cgi (accessed on 9 September 2016).

66. NCBI. Avaliable online: http://www.Ncbi.Nlm.Nih.Gov/ (accessed on 9 September 2016).

67. Liu, R.H.; Meng, J.L. Mapdraw: A microsoft excel macro for drawing genetic linkage maps based on given genetic linkage data. Yi Chuan 2003, 25, 317-321. [PubMed] 
68. Xing, L.; Zhang, D.; Li, Y.; Shen, Y.; Zhao, C.; Ma, J.; An, N.; Han, M. Transcription profiles reveal sugar and hormone signaling pathways mediating flower induction in apple (malus domestica borkh.). Plant Cell Physiol. 2015, 56, 2052-2068. [CrossRef] [PubMed]

69. Livak, K.J.; Schmittgen, T.D. Analysis of relative gene expression data using real-time quantitative PCR and the $2^{-\Delta \Delta C t}$ Method. Methods 2001, 25, 402-408. [CrossRef] [PubMed]

70. Liguori, G.; Weksler, A.; Zutahi, Y.; Lurie, S.; Kosto, I. Effect of 1-methylcyclopropene on ripening of melting flesh peaches and nectarines. Postharvest Biol. Technol. 2004, 31, 263-268. [CrossRef]

71. Cao, L.; Zhao, C.; Su, S.; Luo, C.; Han, M. The role of $\beta$-hexosaminidase in peach (prunus persica) fruit softening. Sci. Hortic. 2014, 169, 226-233. [CrossRef]

(C) 2016 by the authors; licensee MDPI, Basel, Switzerland. This article is an open access article distributed under the terms and conditions of the Creative Commons Attribution (CC-BY) license (http:/ / creativecommons.org/licenses/by/4.0/). 